\title{
A enchente de 2010 em união dos palmares - al: os impactos sócioambientais das áreas ribeirinhas
}

\author{
A flood of 2010 in União dos Palmares -AL: social and environmental impacts in coastal areas \\ Manoel Simeão Moreira; Maria Aparecida da Silva' \\ 'Universidade Estadual de Alagoas - UNEAL
}

\begin{abstract}
Resumo
O objetivo deste artigo foi analisar os reflexos que os impactos socioambientais causaram ás áreas ribeirinhas do Rio Mundaú em União dos Palmares-AL após a enchente de 2010. As áreas mais afetadas foram as que ficam às margens do Rio Mundaú e seu afluente Riacho Cana Brava, os quais sua população ribeirinha tinha quantidade significativa pessoas. A Metodologia que utilizamos foi à pesquisa bibliográfica e a observação das áreas atingidas, através de visitas in lócus antes, durante e depois da enchente. O ocorrido foi uma grande enchente que devastou essas áreas ribeirinhas, deixando muita gente desabrigada e desalojada, destruindo a parte estrutural e os sonhos das pessoas. Além da mudança na vida social das pessoas e no meio ambiente, houve também mudanças significativas na paisagem das áreas ribeirinhas do Rio Mundaú. As margens do rio foram alteradas completamente, onde antes era ocupada por casas e um fluxo intenso de moradores, atualmente vê-se apenas escombros, matagal e áreas isoladas, completamente abandonadas por seus antigos moradores e pelo poder público. Por estar abandonada há o risco de invasões de pessoas sem teto ou até mesmo antigos moradores, que não têm uma perspectiva de conquistar moradias melhores. A enchente foi um divisor de águas na história recente de União dos Palmares, quando se fala de infraestrutura e surgimento de novos bairros, pois ainda que com a criação de conjuntos habitacionais precários e com um avanço do desenvolvimento estrutural, isto proporcionou um desenvolvimento econômico para a cidade e algumas melhorias para a população.
\end{abstract}

Palavras-chave: Enchente, Problemas socioambientais, União dos Palmares.

\begin{abstract}
The aim of this paper was to analyze the impacts that social and environmental impacts caused to areas border the Rio Mundaú in Uniao dos Palmares-AL after the flood of 2010. The areas most affected were the ones that are on the river and its tributary creek Mundaú Cana Brava, which its population had significant amount riverside people. The methodology we used was the literature and observation of the affected areas, through visits in locus before, during and after the flood. What happened was a great flood that devastated these riparian areas, leaving many people homeless and displaced, destroying the structural and dreams of people. Besides the change in the social life of the people and the environment, there were also significant changes in the landscape of the riverside areas of Rio Mundaú. The river banks have been changed completely, which was once occupied by houses and a heavy flow of residents currently see only debris, scrub and isolated areas, completely abandoned by their former inhabitants and the government. By being abandoned for the risk of invasions of homeless people or even old residents, who have no prospect of achieving better houses. The flood was a watershed in the recent history of Uniao dos Palmares, when it comes to infrastructure and development of new neighborhoods, because even with the creation of precarious housing and structural development of a breakthrough, it provided an economic development for the city and some improvements for the population. Keywords: Flood, issues social and environmental, areas riparian.
\end{abstract}




\section{I.INTRODUÇÃO}

Percebe-se que o crescimento acelerado e desordenado das cidades acarretou vários problemas urbanos, e em União dos Palmares isso não é diferente, pois à medida que o município se desenvolve, fica notório que o problema de se ter áreas ribeirinhas ocupadas indevidamente é preocupante para o poder público e para os próprios moradores. $\mathrm{O}$ presente artigo retrata o evento da enchente ocorrida em União dos Palmares-AL, em junho de 2010, evento este que devastou o espaço físico, destruiu sonhos, mudou o curso de histórias de vidas, levando a morte de algumas famílias e centenas de desabrigados, impactando o meio ambiente local, principalmente as áreas ribeirinhas, aumentando a degradação, que outrora fora deteriorado pela ação do homem, visando mostrar os impactos socioambientais. Dando uma ênfase maior a parte ribeirinha focalizando os principais impactos socioambientais enfrentados pela população ribeirinha. Como o espaço social, econômico e cultural foi transformado pela ação das águas.

Procurando analisar os impactos socioambientais e também a força e a dimensão descomunal dessa enchente nunca vista igual em nossa cidade (União dos Palmares - AL), catástrofe que trouxe pânico, horror e incertezas aqueles que conseguiram sobreviver a tantos dias de chuvas torrenciais que culminou com aquele fatídico 18 de junho, uma sexta-feira que se tornou emblemático na vida dos habitantes de União dos Palmares - AL.

Abordamos também os cuidados no monitoramento do Rio Mundaú, os investimentos do poder público que geraram, mesmo ante as incertezas, perspectivas de dias melhores para aquelas populações ribeirinhas que tanto sofreram com a enchente que os abateu. Procura ainda abordar a relação que se terá com o meio ambiente local as margens do Rio Mundaú, na preocupação de plantar a mata ciliar (que antes não existia), a reconstrução de novas estruturas e até se fala na criação de um parque botânico municipal como área de lazer para os cidadãos dessa cidade.

Por fim é crescente o pensamento de estudiosos locais e de especialistas que prevêem que, o evento da enchente ocorrido em 2010 poderá vir como mais força uma década depois, vez que esse ciclo chuvoso em nossa cidade ocorre a cada dez anos e é preciso que quando este evento climático volte a ocorrer estejamos preparados para assim evitar perdas de vidas, móveis, estruturas e isto só será feito por meio do monitoramente constante em época de inverno, pois a prevenção não evitará a inundação, mais evacuará as áreas ribeirinhas preservando principalmente a vida humana.

\section{ESPAÇO URBANO, PAISAGEM E LUGAR}

Segundo Corrêa (1995, p. 07), o espaço urbano é o "conjunto de usos da terra é, em realidade, a organização espacial da cidade; simplesmente, o espaço urbano, que aparece assim como espaço fragmentado". E esse uso da terra é feito muitas vezes de forma irregular, um exemplo são as áreas ribeirinhas ${ }^{1}$ que passam a serem ocupadas, principalmente quando estão localizadas nas áreas urbanas.

O espaço urbano envolve a cidade, espaço de relações sociais, culturais e econômicas entre as pessoas. Onde as sociedades se organizam e se desenvolvem, ao longo da história. Esta sociedade sempre em constantes mudanças, ou seja, vive em um processo continuo de reorganização, devido à heterogeneidade dos agentes que estão envolvidos no processo de desenvolvimento do espaço urbano. O espaço urbano também pode ser conhecido como espaço geográfico, categoria geográfica que pode ser definida por Andrade (1998, p. 28) como "o espaço geográfico é artificial, produzido pela sociedade de acordo com o nível de desenvolvimento e com os sistemas econômicos e sociais dominantes". Pois a própria sociedade é quem produz o espaço geográfico.

O espaço urbano é dinâmico, sua produção e reprodução ocorrem diariamente e constantemente. A organização e reorganização deste espaço, afirmam a supremacia de uma elite dominante em detrimento de uma maioria pauperizada, sobre isto nos diz Ana Fani: “... a produção espacial é expresso das contradições da sociedade que aparece na paisagem pela justaposição de riqueza e pobreza, beleza e fealdade".

A paisagem tem uma relação com a história, pois é através das modificações das paisagens que identificamos a ação do tempo no espaço. Segundo Dollfus (1991, p. 11) "toda paisagem que reflete uma porção ostente as marcas de um passado mais ou menos remoto, apagado ou modificado de maneira desigual, mas sempre presente".

"A paisagem, em seu sentido mais amplo,
é moldada não só pelos processos naturais,
mas também pelos sociais. As condições
climáticas são indiscutivelmente os prin-

1 Aquelas áreas onde há interação entre a terra e corpos com superfície flutuante na água. 
cipais agentes condutores da diversidade das formações vegetais e dos processos das formações dos solos. No entanto, o uso e a ocupação desse mesmo solo têm um poder de modificação da paisagem, [...]' (ARAÚJO, 2004. p. 208)

"A paisagem não só é produto da historia como também reproduz a historia, a concepção que o homem tem e teve do morar, do habitar, do trabalhar, do comer e do beber, em fim, do viver. (CARLOS, 2008. p. 38). A paisagem vive em constante modificação, devido á ação do homem. Ao observar o espaço urbano nota-se que uma paisagem é diferente uma da outra, pois são os movimentos impostos pelo homem através do seu trabalho, cultura e emoção, que transforma a paisagem. Mas nem sempre essa modificação é a destruição do meio natural, pois pode ser a construção de uma paisagem organizada, ou seja, a construção de uma cidade. Essa paisagem urbana é uma ação continua e combinada com o meio natural, ou seja, uma ação consciente do ser humano. Através da paisagem é possível identificar de forma visual as modificações que ela sofreu deste o desenvolvimento do ser humano.

Para o geógrafo a paisagem é um verdadeiro mosaico, percebido através de vários elementos, sejam eles concretos, abstratos, visíveis ou invisíveis, mas que são materializados através das relações estabelecidas entre o meio e o homem, que mostra a organização de todos os elementos no espaço urbano. A partir da idade dos metais o homem começou a se organizar em grupo, tendo assim uma capacidade maior de organização e transformação do espaço. Assim, "o grupo organiza o espaço em função de seu sistema econômico, de estrutura social e das técnicas de que dispõe." (DOLLFUS, 1991. p.33). A paisagem é um elemento concreto das ações da sociedade através do trabalho.

Dentro dos espaços urbanos encontra-se as paisagens, visto que essa paisagem é percebida como um lugar com características próprias, para quem a vivencia, transformando assim em lugar. Lugar este que é uma parte do espaço onde o ser humano tem uma identidade e cria raízes que dão um significado singular. Segundo Carlos (2008. p.52) "o lugar é construído como condição para a reprodução e para a vida, e ao serem construídas, essas condições produzem um espaço hierarquizado, diferenciado, dividido, contraditório, que se consubstancia como um dado de vida [...]". O lugar tem sentido diferenciado para cada pessoa, pois cada um identifica um espaço geográfico como um lugar no qual faz algum sentido na sua vida.

Geralmente os lugares são espaços familiares, fazem parte da vida das pessoas. Partindo dessa afirmação pode-se dizer que cada pessoa tem seu próprio lugar, pois cada parte do espaço tem um significado diferente para quem nele vive. Segundo Santos (2004, p.152) "o lugar é, antes de tudo, uma porção da face da terra identificada por um nome." A modernização dos recursos e a combinação das diferentes características de recursos fazem com que os lugares si diferenciem uns dos outros. As características dos lugares são diferentes, devido o trabalho e a cultura, diversificada de cada grupo social que se relaciona nesse espaço familiar, também chamado de lugar. Assim "o lugar é, pois, o resultado de ações multilaterais que se realizam em tempos desiguais sobre cada um e em todos os pontos da superfície terrestre." (SANTOS 2004, p. 258).

\section{O RIO MUNDAÚ E A ÁREA URBANA DO MUNICÍPIO DE UNIÃO DOS PALMARES - AL}

União dos Palmares é um município alagoano fundado em 13 de outubro de 1831, quando foi desmembrado do município de Atalaia conquistando assim sua autonomia administrativa. E considerado um dos mais antigos do estado de Alagoas e se desenvolveu ás margens do Rio Mundaú. O município de União dos Palmares está localizado na região norte-nordeste do Estado de Alagoas, limitando-se ao norte com os municípios de São Jose da Laje e Ibateguara; ao sul com Branquinha; a leste com Joaquim Gomes; e a oeste com Santana do Mundaú. A superfície do município ocupa uma área territorial de aproximadamente $429,6 \mathrm{~km}^{2}$, Com uma população de aproximadamente 62.358 habitantes (IBGE, 2010). A sede do município se encontra edificada a margem esquerda do Rio Mundaú, com uma altitude de aproximadamente $155 \mathrm{~m}$ acima do nível do mar, a uma distancia da capital, Maceió, de aproximadamente $76 \mathrm{~km}$, tendo seu acesso até a capital pela BR-104.

O município de União dos Palmares está inserido na Bacia na Hidrográfica do Rio Mundaú, que atravessa o município a SSW. Os principais afluentes são o Rio Canhoto que nasce na cidade de Canhotinho, estado de Pernambuco e encontra-se com o Rio Mundaú no Distrito de Rocha Cavalcante, distrito conhecido como "Barra do Canhoto, Rio de Inhumas, Rio Seco, Rio Sueca, 
Rio caruru, Rio Cana Brava e os Riachos do Timbó, Pindoba, Pichilinga, Murici, Rego Fundo, Cabeça de Porco, Canoa, Tatu, Pelada, bebida, Grota do Negro e Macacos.

O Rio Mundaú nasce no município de Garanhuns a cerca de $750 \mathrm{~m}$ de altitude e segue uma direção geral noroeste - sudeste ao longo dos seus $150 \mathrm{~km}$ extensão. E tem uma extensão de $141 \mathrm{~km}$ é um rio perene, com área de 4.126 $\mathrm{km}^{2}$ e vazão média de $30,6 \mathrm{~m} 3 / \mathrm{s}$.O médio curso do Rio Mundaú abrange cotas variando de 500 (quinhentos) a 200 (duzentos) metros, cujo relevo se apresenta ainda bastante acidentado. Sua Bacia Hidrográfica possui uma área total de $8.061 \mathrm{~km}^{2} \mathrm{e}$ contribui com o volume médio de $20.407,36 \times 105 \mathrm{~m}^{3}$ ao ano de água, disponível ao escoamento superficial e a recarga dos aqüíferos subterrâneos. O padrão de drenagem predominante é o dendrítico. Todo esse sistema fluvial deságua no complexo Laguna-Mundaú e por fim no Oceano Atlântico.

A área urbana do município de União dos Palmares é formada pelos bairros de: Roberto Correia de Araújo (conhecido popularmente como terrenos), Nossa Senhora das Dores (conhecido como Vaquejada),Conjunto Sagrada Família ( antigo mutirão), Abolição, Costa e Silva, Abdon Veríssimo I e II, Conjunto Nilton Pereira (casas novas), Cohab Velha e Nova, Jaguaribe, Conjunto Padre Donald (morro das cobras), Loteamento Santa Maria Madalena, Conjunto Zumbi dos Palmares (em processo de construção), Alto do Cruzeiro, Residencial Morada das Arvores, Bairro de Fátima, Jardim Brasília e Centro. Desse total de bairros uns oito possuem saneamento e ruas ou, em paralelepípedo ou asfaltada e um restante com ruas de terra batida e com esgoto a céu aberto e os que mais sentem a ausência desse serviço que é dever do poder público realizar, promover são os bairros periféricos. Dentre esses bairros um dos que foram afetados também pela enchente foi o bairro Jaguaribe, no qual existe uma depressão topográfica na praça central do mesmo e assim as águas tomaram conta, invadiram parte daquele logradouro. Alguns bairros da cidade surgiram em decorrência de enchentes que aconteceram ao longo da historia de União dos Palmares, como por exemplo, os bairros Conjunto Sagrada Família, Conjunto Padre Donald, Bairro de Fátima, Conjunto Zumbi dos Palmares e Conjunto Nilton Pereira. Assim a cidade esta expandindo sua área urbana no sentido leste.

Em União dos Palmares tem vários bairros que tem sua localização em partes altas: bairros Cohab Velha e Nova, Costa e Silva, Alto da Boa Vista, Jardim Brasília, Bairro de Fátima, Loteamento Santa Maria Madalena, o que ajuda a preservar vidas quando da ocorrência de inundações nas partes baixas, ao contrário de outras cidades em que a área urbana fixa bem no vale do rio o que provoca inundação na cidade por completo.

\section{AS ÁREAS RIBEIRINHAS E A ENCHENTE OCORRIDA EM JUNHO DE 2010}

As áreas onde reside a população ribeirinha da cidade de União dos Palmares localizam-se às margens do Rio Mundáu e de seus principais afluentes, o Rio Cana Brava, o Riacho Macacos, o Rio Caruru, o Rio Canhoto, o Rio Seco, os Riachos do Timbó e Pindoba, o Rio Sueca, os Riachos das Inhumas que nasce na cidade de

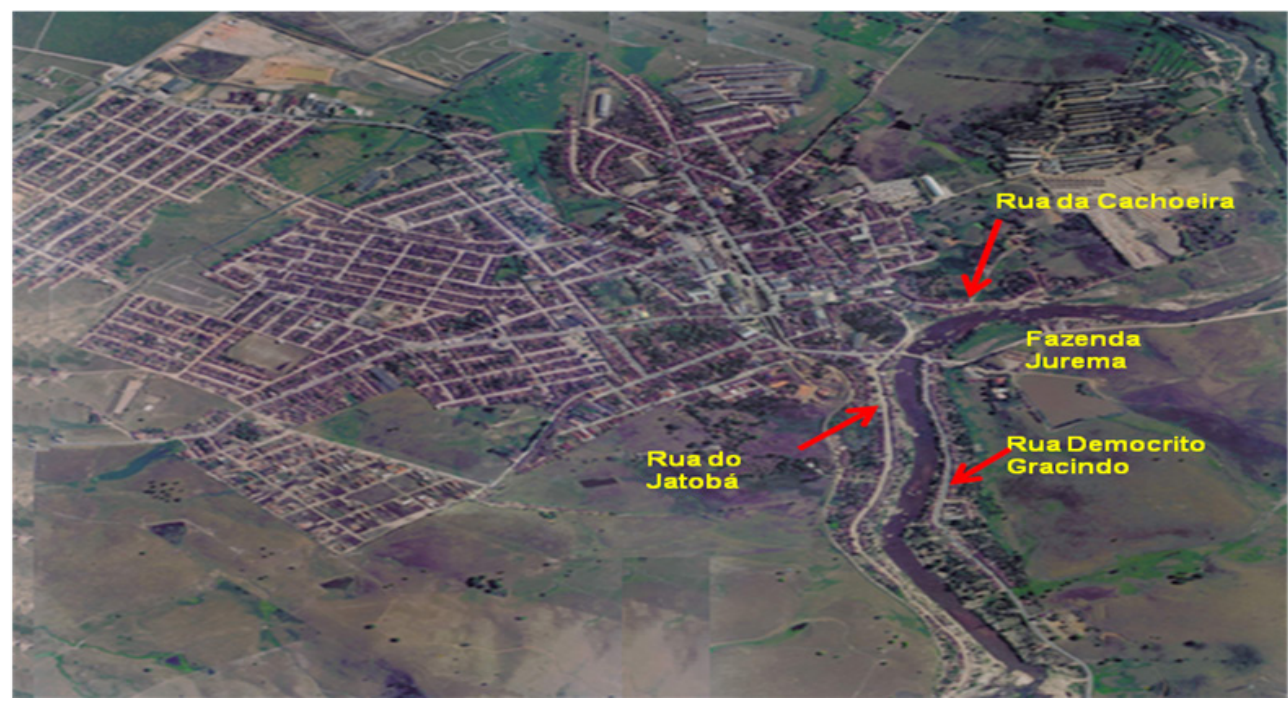

Figura1 - Área de União dos Palmares em destaque as ruas ribeirinhas ao rio Mundaú. Fonte: Plano Diretor do Município, 2006. 
Brejão no Estado de Pernambuco e Pichilinga, os Riachos Murici, Rego Fundo e Cabeça de Porco, os Riachos Canoa, Tatu, Pelada, Bebida e Grota do Negro. A ocupação das áreas ribeirinhas em União dos Palmares ocorreu gradualmente ao longo da história de constituição desta cidade, as residências foram construidas muito perto de onde antes havia a mata ciliar e ao desmatar-se está área, acelerou o processo de erosão que por sua vez gerou o assoreamento do rio Mundáu.

Dentre as ruas localizadas em áreas ribeirinhas nesta cidade, as que apresentam maior importância devido ao contingente populacional e a proximidade das mesmas em relação ao leito do rio são as ruas: Democrito Gracindo, Rua do Jatobá e Rua da Cachoeira, localizada no antigo centro de Uniao dos Palmares, conforme apresentado na figura 1.

A destruição foi quase que perda total nestas ruas mencionadas, pois centenas de residencias, casas comerciais e as pequenas produções animais e agrícola foram levadas pelas águas. $\mathrm{Na}$ outra parte da cidade, onde localiza-se o Rio Cana Brava também houve destruição,uma fabrica de laticinios foi destruida causando o desemprego e o seu fechamento, um posto de gás naturtal teve suas dependencias inundada pelas águas, o muro que circundava a fábrica de laticinios caiu e os intullhos de móveis quebrados e de lixo tomaram as Avenidas João Lyra Filho, Antonio Gomes de Barros e Praça Santa Quitéria, mecionamos também as ruas Alonso Costa Pereira, Roberto Alfredo do Vale Silva, parte da Orlando Gomes de Barros, Edivar Lopes e a baixada da Rua José Hortêncio de Souza, ruas pertencentes ao Bairro Roberto Correia de Araújo conhecido popularmente como "terrenos", como observar-se na figura 2.

A inundação foi tão intensa que as águas chegaram até a ladeira de acesso ao Hospital São Vicente de Paulo onde nunca antes havia chegado e todo esse conjunto de destruição mexeu com a estrutura de União dos Palmares, o que antes apenas atingia as áreas ribeirinhas e logo que passava a enchente as pessoas voltavam para suas casas, as ruas do centro não eram atingidas e a destruição não havia sido em grande escala, dessa vez não, os rios Mundaú e Cana Brava patrocinaram destruição medo e incertezas envolvendo a cidade como um todo e a mesma passou semanas e meses se recuperando, tudo em um processo lento que perdura até os dias de hoje e levará mais um tempo para que tudo volte ao normal.

"Naquela manhã de sexta-feira, 18 de junho, saí de casa, na rua Orlando Gomes de Barros, Bairro Roberto Correia de Araújo e fui trabalhar na parte alta da cidade, chovia muito e prometí a minha esposa que voltaria para o almoço. A chuva foi contínua o dia todo e a noite já não voltei para casa, me abriguei na residência de minha mãe com esposa e filho, para a nossa surpresa faltou energia e as águas invadiram a rua em que estavámos foi então que fomos para a casa de meu irmão e lá a água chegou também, nisto uma amiga nos levou para a casa da tia dela onde eu, esposa, filho e um sobrinho ficamos abrigados. No dia seguinte pedí a minha esposa para ir a nossa casa, para limpá-la e voltarmos para a mesma, como ela estava demorando, fui com um amigo até lá, e ao passar pela Avenida Antonio Gomes, João Lyra Filho e a Rua que morava e ver lama, o muro da fabrica caido, muita água, móveis quebrados jogados nas ruas, fui ficando preocupado e a ficha caiu, percebí

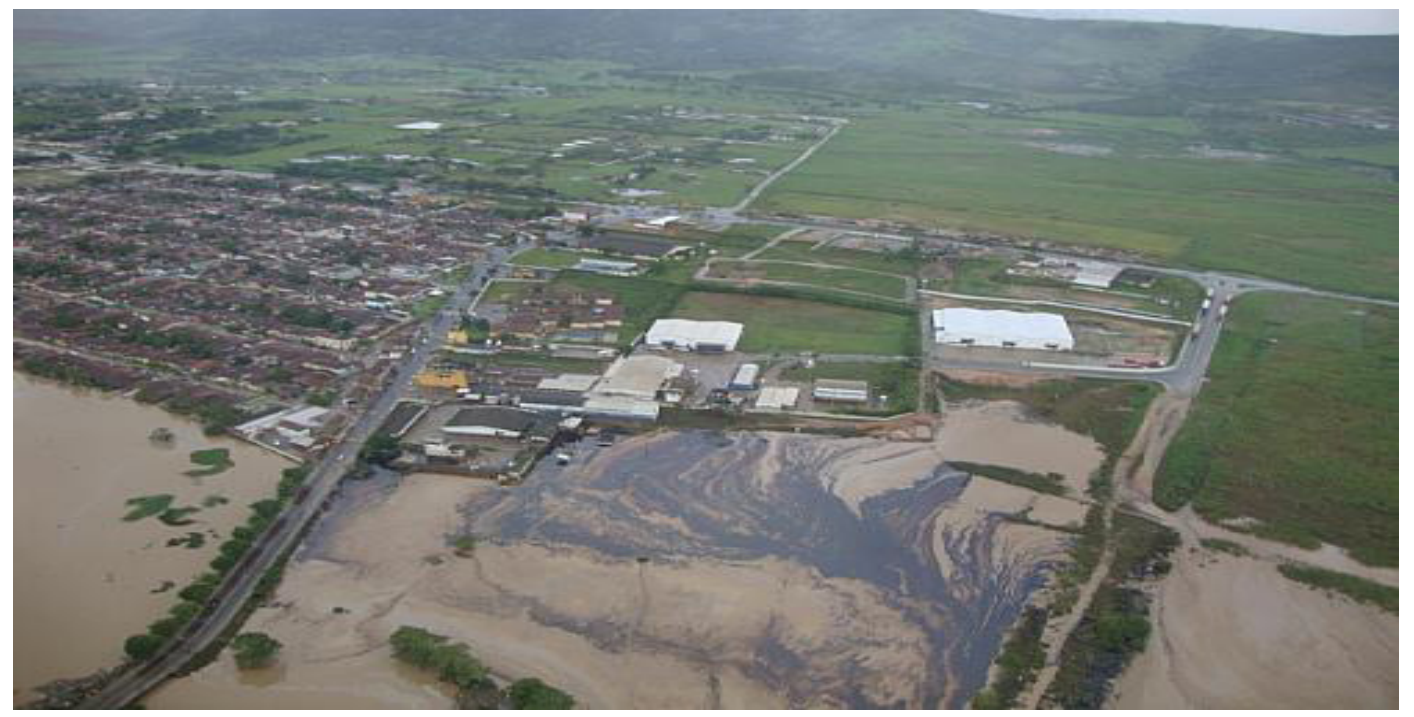

Figura 2- vista área do Rio Cana Brava no Bairro Roberto Correia de Araujo.

Fonte: www.alagoas24 horas.com. br/09.03.2012 
que a minha casa havia sido atingida e ao chegar nela, ví a marca d'água na parede, na altura de quase dois metros, nossos móveis, documentos e roupas em meio a lama e a destruiçãol. A enchente mexeu com as nossas vidas e a promessa que fiz a minha esposa , naquela manhã de 18 de junho , promessa de no almoço voltar ao nosso lar, perdeu-se no tempo e nós nunca mais voltamos para a referida casa. Vendí a casa e comprei uma outra em um local em que a enchente não chega. As imagens daquela noite de horror ficarão para sempre em minha memória, pois aquela enchente em União dos Palmares em 2010 foi um divisor de águas para nós moradores palmarinos, pois forçou mudanças em nossas vidas ". (sic) (Manoel Simeão Moreira-Morador da Rua Orlando Gomes de Barros, $n^{\circ} 28 \mathrm{~B}$, rua atingida pela enchente em Depoimento)

As enchentes são calamidades que ocorrem quando um leito de um rio recebe um volume muito grande de água, sendo impossível suportar a quantidade de água o rio transborda e inunda as suas margens. Porém quando isso ocorre às áreas urbanas são as que sofrem mais e as que padecem com prejuízos, pois são geralmente ocupadas pela população. Isso se dar devido à interferência do ser humano que sem medir as conseqüências funda as cidades em limites com os rios. Essa vulnerabilidade de perdas que atingiu a população das ruas ribeirinhas se deu por causa da ocupação do espaço indevido, foi o que ocorreu nessa enchente e em tantas outras que já se abateu sobre União dos Palmares, onde uma população de quantidade estimável igual as das ruas Demócrito Gracindo (antiga Rua da Ponte), Jatobá, Juazeiro e Cachoeira, deixaram de existir (foram transferidas para outros locais), nestas transferências suas relações sociais foram interrompidas, e houve ainda perdas significativas materiais e humanas, ocorridas devido a simplesmente ocuparem o espaço as margens do Rio Mundaú. Segundo Souza:

"á pobreza urbana e á segregação residencial podem ser acrescentados outros problemas, não raro intimamente associados com as duas. Um deles é o da degradação ambiental, em relação á qual, aliás, se percebe, em cidades como as brasileiras, uma interação entre problemas sociais e impactos ambientais de tal maneira que vários problemas ambientais, que irão causar tragédias sociais (como [...] enchentes $[\ldots])$, têm origem em problemas sociais ou são, pelos menos, agravados por eles." (SOUZA, 2007. p.84).
As enchentes ${ }^{2}$ são vistas como calamidades naturais, mas na verdade são conseqüências das ações sociais do ser humano ou a falta delas. È bom ressaltarmos que por mais ações que se faça, por mais monitoramento que se tenha e ainda que todas as ações humanas estejam aplicadas, adequadas e executadas das formas mais corretas possíveis, ainda assim as calamidades irão ocorrer, vez que a força da natureza é incontrolável. São movimentos involuntários, é uma dinâmica sem controle, fora dos padrões de controle e assim mesmo com todos os cuidados e prevenções apenas se diminuirão os efeitos, as conseqüências, mas o evento das enchentes ou quaisquer outros fenômenos serão apenas minimizados e nesse caso áreas serão evacuadas em tempo hábil, mas o evento acontecerá com efeitos menores, sem vidas perdidas, sem maiores problemas sociais que causem o deslocamento e desalojamento de um grande número de pessoas, mas que ocorrerão quanto aos fenômenos naturais o homem até diminui os efeitos da devastação por ele provocada, mas não os impedem de acontecer.

O evento da enchente ocorrido no mês de junho do ano de 2010 se intensificou em União dos palmares e região devido à grande quantidade pluviométrica que caiu sobre a nossa cidade, foram vários dias de chuva atingindo mais de uma semana aonde riachos, pequenos regatos e afluentes do Rio Mundaú encheram, transbordaram provocando a grande catástrofe que todos presenciaram , trazendo prejuízos para todos os habitantes do nosso município, pois direta ou indiretamente todos foram afetados. Há de se ressaltar que tal evento climático prejudicou o comercio local, a produção rural e mudou de certa forma para sempre a vida de parte daqueles palmarinos que aqui vivem. Como podemos observar na figura 3 , uma área que apresentava alguns estabelecimentos comerciais que foram destruídos pela ação das águas e há também uma elipse que mostra a ponte Abdon, parcialmente destruída.

A enchente teve o seu ápice na sexta-feira dia 18 de junho do ano de 2010, começando a invasão do rio Mundaú a nossa cidade no inicio da tarde levando pânico aqueles que moram as margens e até daqueles que moravam em partes altas da cidade, vez que União começava a ficar ilhada, as rodovias foram interditadas devido às águas as terem invadido. Essa enchente foi de tal dimensão que chegou a alagar parte do centro

2 Enchente ou cheia é, geralmente, uma situação natural de transbordamento de água do seu leito natural, qual seja, córregos, arroios, lagos, rios, ribeirões, provocadas geralmente por chuvas intensas e contínuas. 


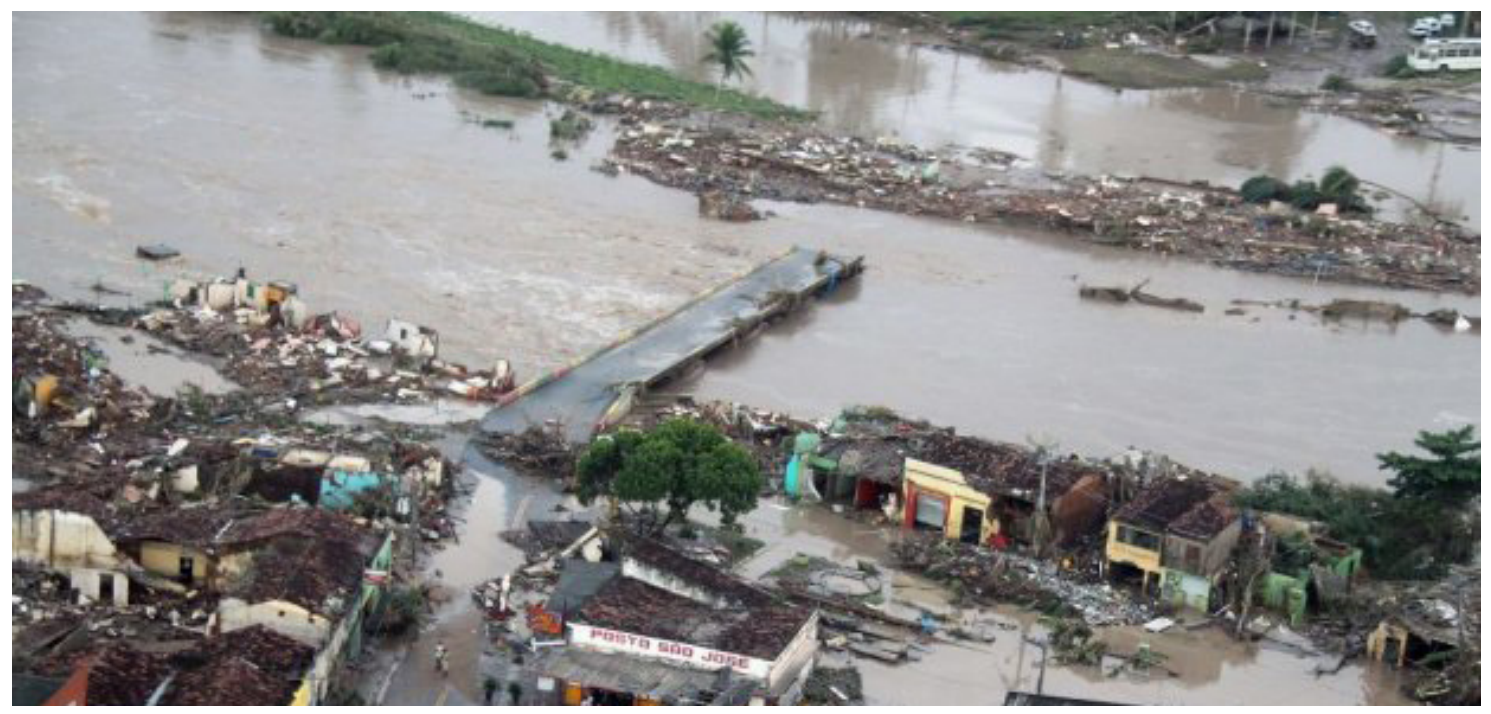

Figura3 - Ponte Abdon Coupertino dos Santos que liga Rua Democrito Gracindo e Jatobá Fonte: www.jornaldelondrina.com.br/09. 03.2012

da cidade, coisa que nunca antes, em enchentes anteriores não havia acontecido.

As águas fecharam os acessos em torno de nossa cidade onde ficam as ruas: Luiz Gomes de Freitas, Demócrito Gracindo (antiga Rua da Ponte), Jatobá, Av. Antonio Gomes de Barros e João Lyra Filho e na baixada do Povoado Caípe próximo ao Posto da Polícia Rodoviária Federal, entrar em União dos Palmares só de barco ou helicóptero, o único acesso a cidade ainda que de forma precária dava-se pela Rua Juvenal Mendonça (conhecida como Castelo Branco) acesso de fluxo dos veículos que vêem do município de São José da Laje e do Estado de Pernambuco.

Além das águas que invadiram as ruas, derrubaram milhares de casas, centenas de postes de energia, além de tudo isto a nossa cidade ficou as escuras devido a toda rede elétrica ter sido arrancada aonde antes ficava a Rua da Ponte, localizada próximo a subestação da Eletrobrás (antiga Ceal). Como percebemos na figura 4.

No dia seguinte após a enchente o que se viu foi um cenário de total destruição, parecia que uma "bomba" havia sido jogada em nossa terra e ainda que um imenso trator tivesse feito um arrastão destruindo tudo a seu caminho e misturando roupas, móveis, veículos e até vidas o que ficava difícil distinguir uma coisa da outra. Também trilhos da linha férrea foram retorcidos como se fossem palitos, enormes tanques de estoques de álcool da Usina laginha foram arrancados e levados pelas águas, pedras enormes foram deslocadas pelas forças das águas e se registrou ainda três mortes de pessoas que não conseguiram sair de suas casas a

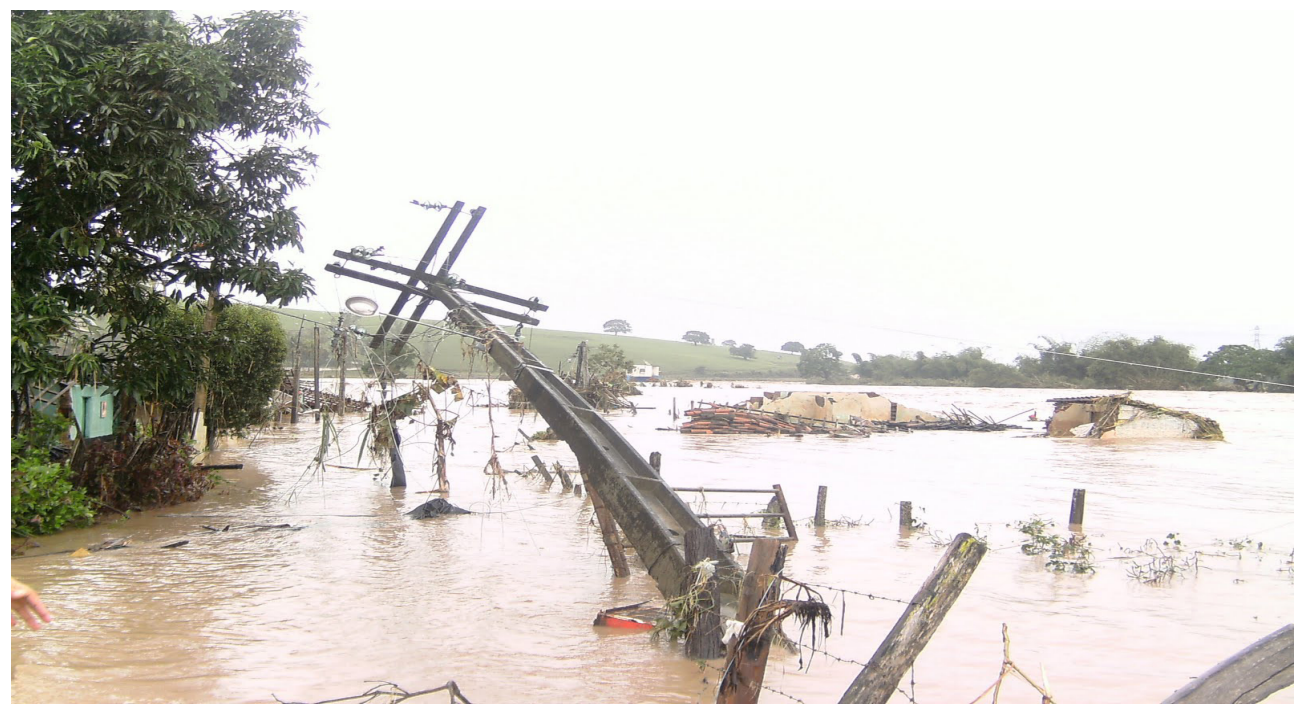

Figura4- Poste de energia elétrica completamente destruída.

Fonte: manoelfeliciano. blogspot.com/20.06.2010 


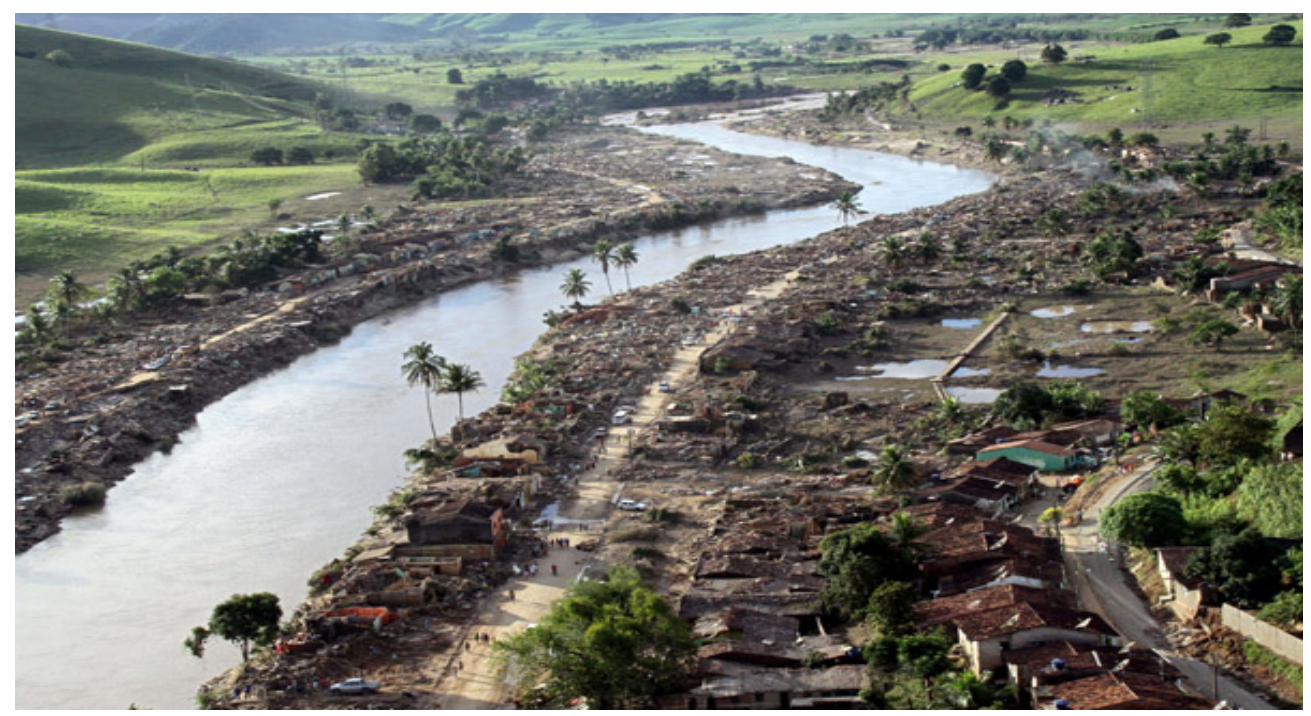

Figura5- Rua Democrito Gracindo e Rua do Jatobá depois da enchente.

Fonte: www.Band.com. br/10.03.2012

tempo. Na figura 5 percebe-se a destruição das ruas citadas:

As enchentes de 1969, 1977, 1989 e 2000 não tiveram a força que a ocorrida em 2010, não foram tão catastróficas e destruidoras de vidas e do espaço físico, elas apenas encheram o rio mundaú não chegando a derrubar as casas localizadas nas Ruas da Ponte, Jatobá, Juazeiro e Cachoeira de modo que quando as águas baixaram as pessoas retornaram as suas residências, fazendo alguns reparos e apenas algumas casas caíram.

Passado mais de um ano da enchente, a vida vai retomando seu curso normal, estradas novas surgiram tal como novos conjuntos habita-

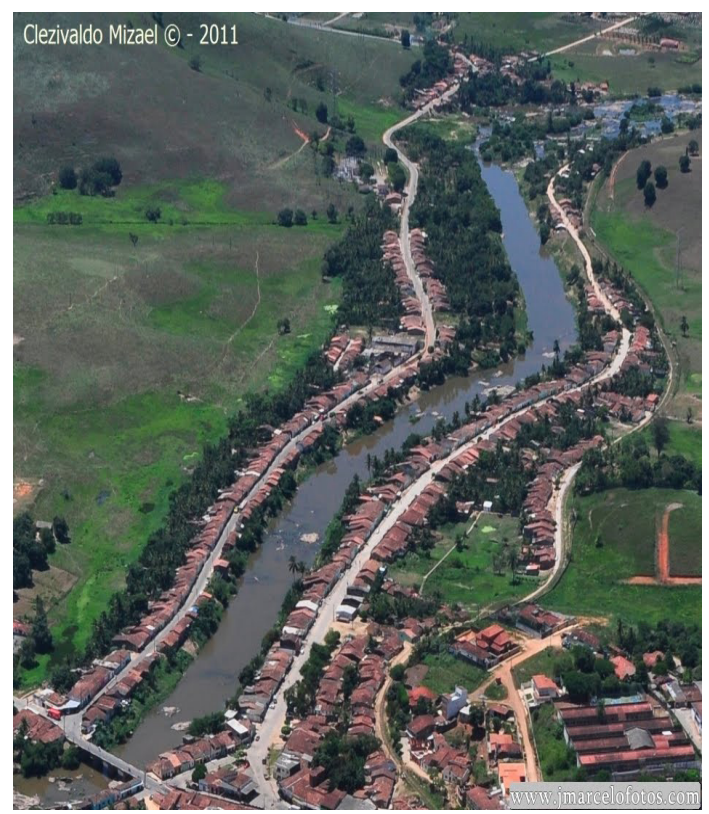

Figura6- paisagem antes da enchente

Fonte: www.jmarcelofotos.com/09.03.2012 cionais para abrigar as pessoas afetadas pelas águas, novas oportunidades de emprego (na construção civil - construção das novas casas residenciais), a cidade teve um aumento em residências e novos empreendimentos (a criação de novos bairros longe das áreas ribeirinhas) e os antigos espaços de moradias passou a ser zona rural, o que antes caracterizava-se como zona urbana. Aqueles que não conheciam União e hoje nos visitam e vão às margens do Rio Mundaú, não imaginam que ali naquele local (margens do rio Mundaú) um dia existiu centenas de residências, comércio, fluxo de veículos, criações de animais em fim vidas em movimento, aquele espaço hoje é um espaço vazio,

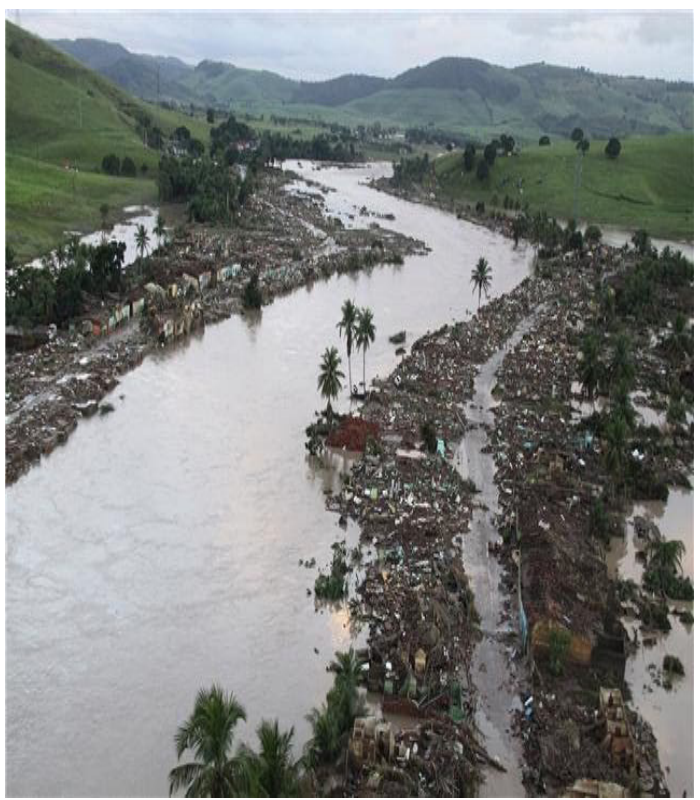

Figura7-paisagem depois da enchente Fonte: www.Band.com.br/10.03.2012 
apenas uma paisagem que ilustra a ausência de vidas e estruturas que se foram e que provavelmente nunca mais será o mesmo, e não terá a dinâmica de outrora. Podemos observar o antes e depois das Ruas Democrito Gracindo e Rua do Jatobá, nas figuras 6 e 7 .

Aquela enchente arrasou também a economia das ruas ribeirinhas, pois naquelas localidades tinha um posto de gasolina, uma fabrica de refrigerante (desativada nas primeiras cheias), um ponto de carros que faziam a linha União dos Palmares a Santana do Mundaú, tinha um pequeno hotel, alguns bares, a festa do padroeiro da rua, escola de informática, feira do gado e feira livre além de mercearias, isso tudo foi extinto com a enchente e devido a grande devastação nada foi reerguido, ainda hoje, um ano e meio depois ver-se ainda os escombros que são testemunhas da tragédia que se abateu em União dos Palmares naquele dia 18 de junho do ano de 2010. Segundo Valente:

\begin{abstract}
"As comunidade passaram a ter relações muito simplista com a água [...] causando perdas humanas e econômicas, ela passou a ser quase uma ameaça. Nada de barro no entorno de casas e dos prédios tudo cimento e asfalto para o conforto dos usuários de carros e assim as águas provenientes das chuvas são logo jogadas em tubulações para prejudicar o ambiente. Mas a natureza tem seus poderes e tais atitudes acabam provocando conseqüências perigosas." (2010, p. 01)

Eventos climáticos acontecem desde a gênese da terra, mas nunca se espera que ocorram com tanta destruição, mas infelizmente às vezes essas incidências de destruição são recorrentes nos lugares como foi em União dos Palmares em junho de 2010, isto interrompeu vidas, modificou a paisagem e o lugar e interferiu para sempre no curso da história da cidade no que tange aos aspectos sociais, físicos e ambientais.
\end{abstract}

\section{OS PROBLEMAS SOCIOAMBIENTAIS CAUSADOS PELA ENCHENTE NAS ÁREAS RIBEIRINHAS DA CIDADE DE UNIÃO DOS PALMARES}

Por passar pelo perímetro urbano, o Rio Mundaú era ladeado por casas, tendo em seu curso as ruas Democrito Gracindo, Rua do Jatobá e Rua da Cachoeira, não havendo qualquer mata ciliar em suas margens. As margens do rio eram muito devastadas pela ação do homem que se apropriou das mesmas ao longo dos anos sem se preocupar com o meio ambiente nem com as conseqüências que poderia acarretar em tempos futuros. As casas tinham seu quintal praticamente dentro do rio, onde muitas das vezes jogavam lixo, outros lavavam louças e roupas, tinha criação de animais como porcos, cavalos, etc., tinham também lava jato onde eram lavados carros e era feito à troca de óleo que conseqüentemente era jogado no rio. Ainda foi construído as margens do rio o matadouro ${ }^{3}$ da cidade, onde muitos dos seus excrementos caiam no lixo.

As margens eram bem desprovidas de vegetação nativa, pois naquele local existia um fluxo intenso de pessoas que tinham relações afetivas, sociais e econômicas. Desde as enchentes anteriores já não havia a mata ciliar, pois à medida que a ocupação irregular foi avançando, nos idos dos anos de 1960, a mata ciliar foi destruída dando lugar a residências. O que restou foi uma reserva de bambus localizada dentro de um assentamento onde antes funcionava a Empresa de Pesquisa Agropecuária de Alagoas - Epeal, conhecida pelos palmarinos como "sementeira" e também na Terra Cavada, uma rua ribeirinha as margens do Rio Mundaú. No ano de 2007 um projeto de rearborização da mata ciliar do Rio Mundaú foi criado e passou a ser coordenado por algumas educadoras da Escola Municipal Mário Gomes de Barros, escola pertencente à rede municipal de ensino, do municipio de União dos Palmares - AL. Como apresenta a figura 8, o desempenho das mesmas.

O projeto se propunha a conscientizar a população das margens ribeirinhas sobre a importância de preservar o rio, revitalizá-lo e rearborizá-lo. O projeto teve uma boa repercussão chegando até ser publicado como uma boa experiência ecológica pelo Jornal Tribuna Independente (AGOSTO, 2007) foi uma matéria publicada em página inteira, mostrando o trabalho das professoras Maria Madalena Monteiro e Maria Madalena Soares com seus alunos, mas apesar da repercussão positiva o projeto não foi adiante, crer-se que por falta de incentivos de órgãos municipais e ambientais e até de recursos financeiros. Os alunos também participaram de forma efetiva do projeto, conforme apresentado na figura 9 .

Caso o referido projeto de recriação da mata ciliar tivesse seguido adiante, hoje aquelas mudas plantadas já seriam pequenas árvores a

3 Lugar onde se abatem reses para consumo público. Reses vêm de rês e significa qualquer quadrúpede usado na alimentação humana. 


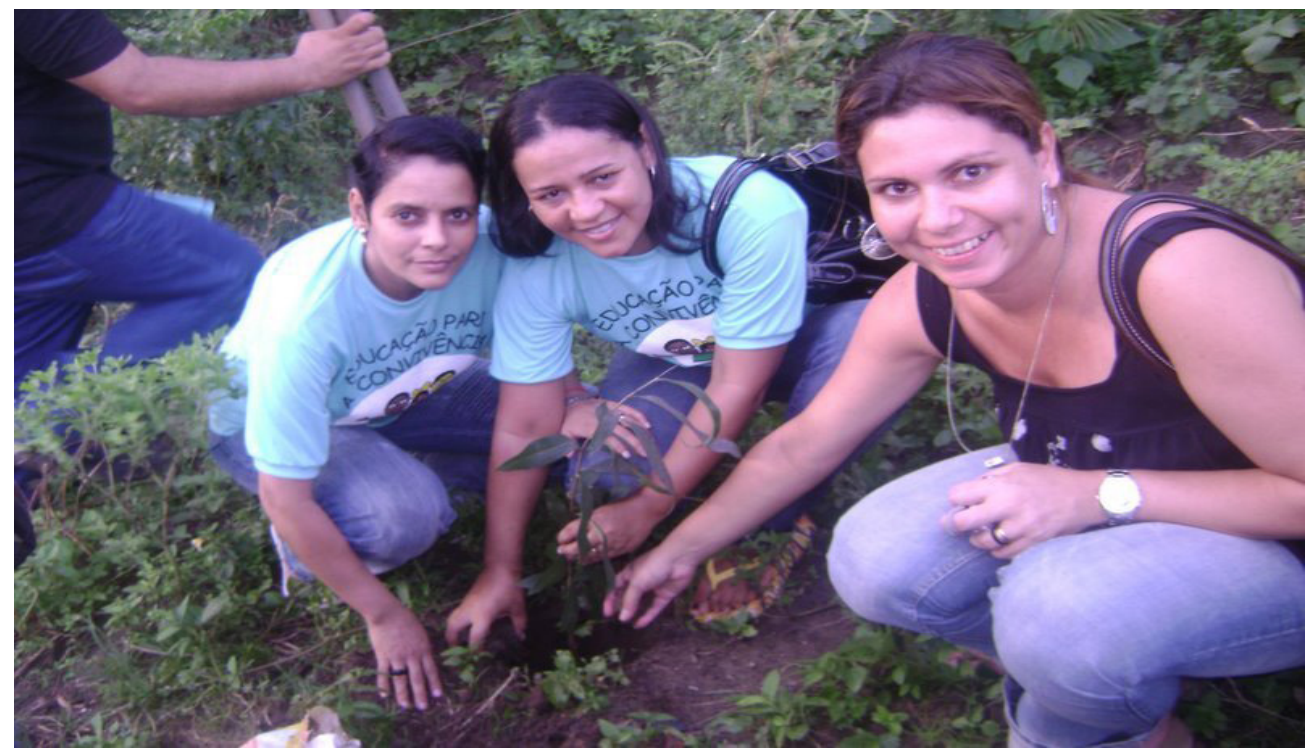

Figura 8 - Professoras idealizadoras do projeto de revitalização.

Fonte: acervo da professora madalena monteiro/2007

delinear aquele espaço meio urbano meio rural que se estendia ás margens do Rio Mundaú. È bom ressaltar que o momento aonde as margens do rio encontram-se desocupadas é mais propicio para rearborizar, replantar a mata ciliar. Por que não existem mais residências e isso facilitaria muito os trabalhos dos alunos e dos técnicos na implantação das mudas que em um período de $4 \mathrm{a}$ 10 anos iriam crescer e formar a nova mata ciliar urbana do Rio Mundaú.

Essa mata ciliar replantada poderia começar na Rua do Taquarí estendendo-se pelas antigas ruas: Rua Demócrito Gracindo (Rua da Ponte), Rua do Juazeiro, Rua do Jatobá, Rua da Cachoeira, Terra Cavada, povoados Jacinto e Caípe. Seria um grande empreendimento positivo para o meio ambiente e para a melhoria da vida do rio, promovendo assim a sua revitalização. Empreendimento este que poderia ter a iniciativa da Secretaria Municipal do Meio Ambiente, com o apoio da Prefeitura Municipal e dos governos do Estado e Federal. A figura 10 apresenta as margens do rio Mundaú em União dos Palmares nos dias atuais. Dentro deste contexto da enchente surgem os problemas sociais relacionados ao espaço, provocados pela enchente e esses problemas refere-se às pessoas que: perderam o emprego (como os empregados do laticínio São Domingos que foi invadida pelas águas e fechou que ficam localizadas as margens do rio Cana Brava, no Bairro Roberto

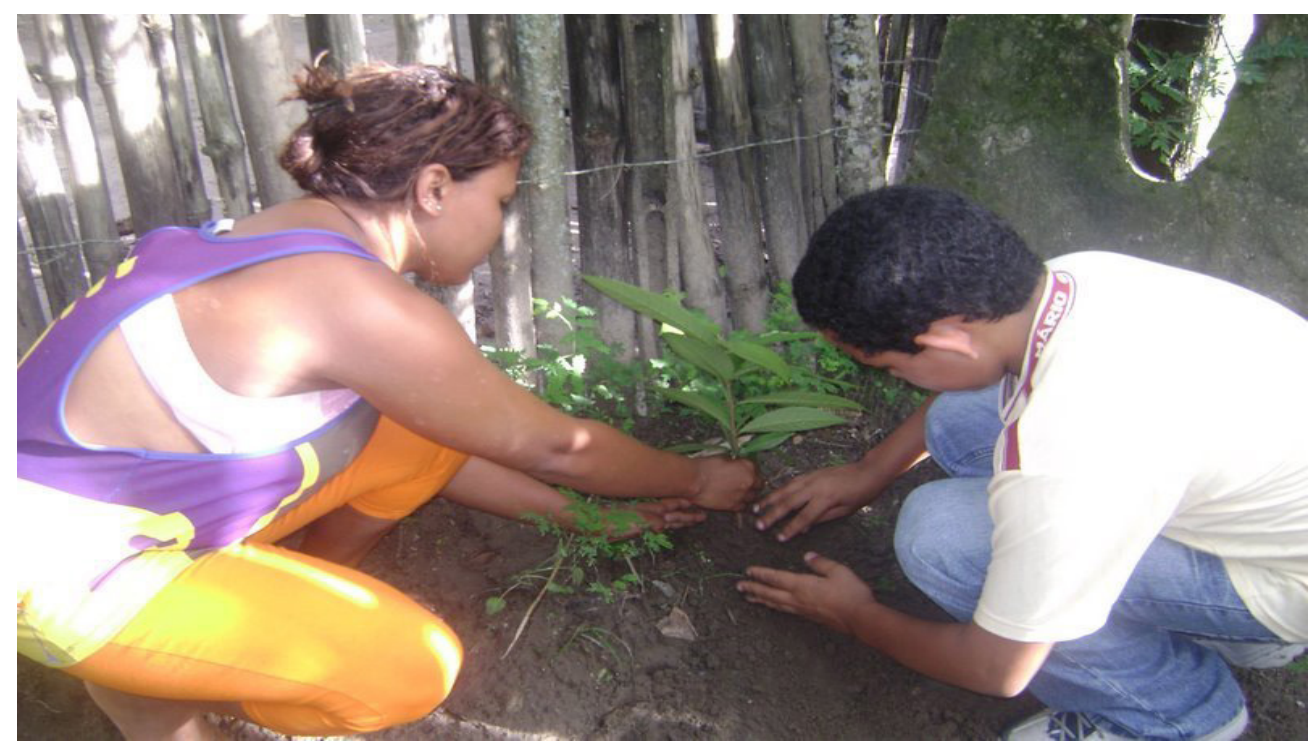

Figura 9- alunos plantando uma muda de árvore as margens do Rio Mundau.

Fonte: acervo da professora Madalena Monteiro/2007 


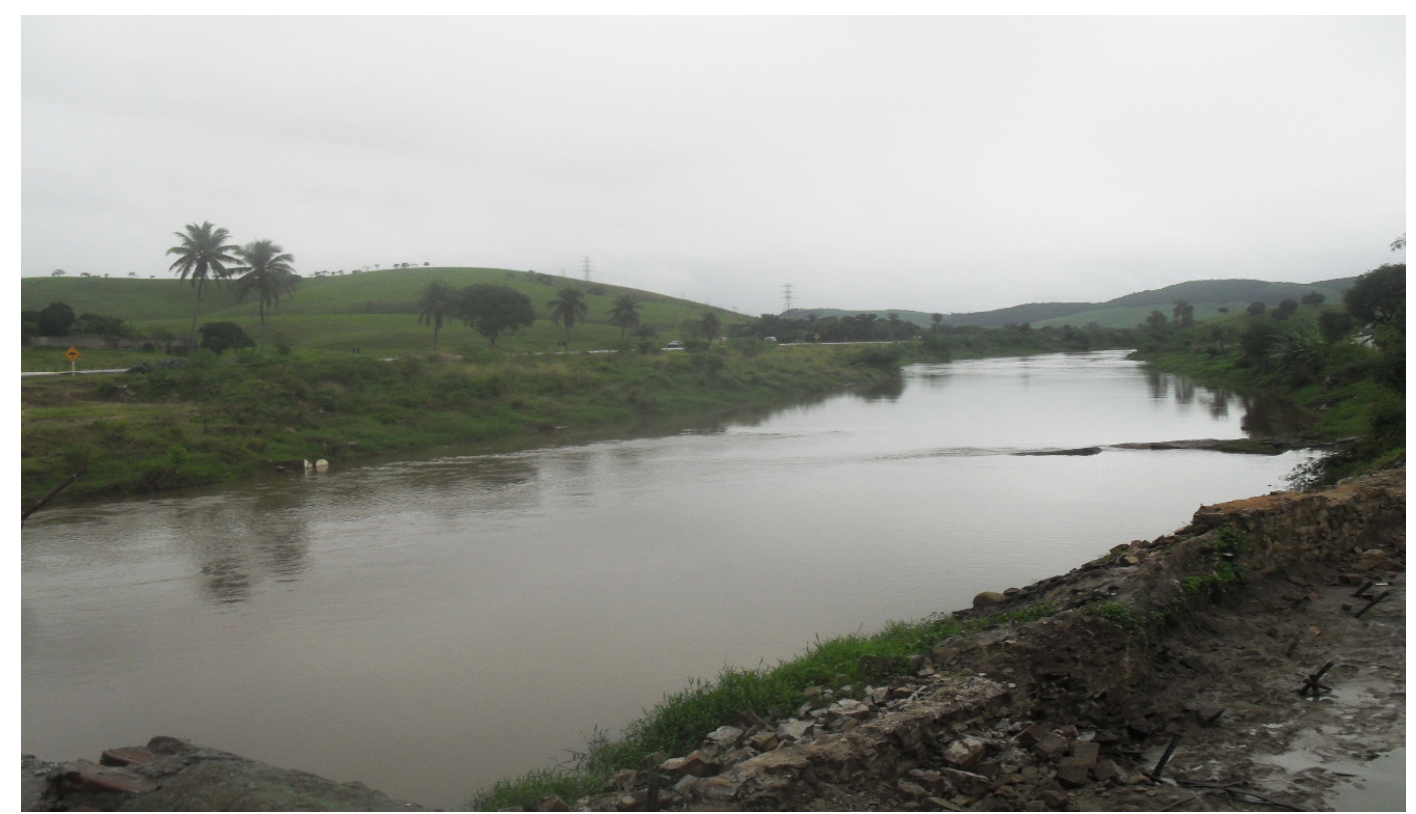

Figura 10- As margens do rio Mundaú um ano depois da enchente.

Fonte: Roberto Martins, 2012

correia de Aarujo), que morreram e que perderam suas casas totalmente, que ficaram desalojadas e até foram afetadas psicologicamente, sem contar o financeiro, haja vista que pequenos proprietários de criações de animais, as margens do rio, perderam as mesmas, desestabilizando-os, e tudo isto provocou uma convulsão social, uma inquietação popular, que precisou de uma resposta firme dos poderes constituídos para debelar ou minimizar essa problemática social a qual a enchente de 2010 provocou na vida das pessoas aqui em União dos Palmares.

Foram desencontros, frustrações e incertezas do futuro, vidas afetadas que as imagens daquela tragédia que os abateram e se incorporou para sempre, na história de cada morador ribeirinho. Pois uma vez afetada a parte social de uma população, provoca males profundos no seio da sociedade, foi o que ocorreu com a população ribeirinha do Rio Mundaú.

Um fato bem presente que ficou marcante para a população ribeirinha na história da enchente de 2010, em União dos Palmares, foi que, dessa vez, por força do poder público e da justiça, os habitantes daquela área não voltarão a construir suas casas as margens do Rio Mundaú, como fazia em enchentes passadas. Isto ocorreu por dois motivos: O primeiro motivo foi que a maioria das casas foi destruída pela força das águas e as que ficaram de pé e em escombros foram demolidas pelas máquinas. O segundo motivo foi que a justiça e o poder público impediram a volta dessa população ribeirinha. $\mathrm{Na}$ possibilidade de vir uma nova enchente, não haverá perdas humanas e materiais, essa área estará desocupada, e assim as águas do transbordamento do rio passará sem maiores problemas.

Nesse contexto pontuamos ainda o avanço da cerca de uma fazenda que fica naquela localidade ribeirinha para bem próximo do Rio Mundaú, prejudicando assim o fluxo de pedestres que passam as margens da $A L-205$, que devido à proximidade dessa cerca não se têm segurança, pois não há acostamento, a cerca avançou sobre o mesmo e segundo o novo Código Florestal Lei PL 1876/99, do Relator Paulo Piau (PMDB ${ }^{4}-\mathrm{MG}$ ) que encontra-se em processo de tramitação no Congresso nacional, preceitua que:

"Para cursos d'água de até dez metros de largura, deve ser recomposta uma faixa de 15 metros de vegetação. Para rios maiores a área deverá ter entre 30 e 100 metros".

Os impactos resultantes da enchente foram colossais, e os mais afetados e que sofreram diretamente foram às pessoas mais humildes, pois após a enchente uma nova malha asfáltica passou por aquelas terras, trazendo benefícios para poucos e perdas materiais e de cunho sentimental para pessoas que antes a esse evento já tinham pouco, e com o mesmo reduziram-se a nada, sendo forçadas pelas circunstancias a recomeçarem do zero, da um novo início as suas vidas.

Além de todos os conturbados fatos, é de se pontuar também, algumas ocorrências que

4 Partido do movimento democrático brasileiro. 
gerou impactos sociais negativos pós enchente para nossa cidade. Fatos como: A falta de energia elétrica por vários dias; o preço da água mineral que chegou a quase dez reais, quando na verdade custavam cinco reais; os supermercados ficaram desabastecidos; o preço da vela subiu devido à falta de energia; a rede elétrica a beira do Rio Mundaú foi arrancada pela força das águas; os preços dos alugueis aumentaram significativamente devido à grande procura; o risco de saques ao comércio foi grande, obrigando os comerciantes a fecharem suas portas; a feira livre sentiu o impacto do desabastecimento e da falta de pessoas para comprar; ruas ficaram destruídas cheias de lamas e moveis quebrados e molhados, jogados nas calçadas iguais a cenas de cidades destruídas por um furacão ou por uma bomba nuclear. As escolas fecharam por tempo indeterminado, até porque acolheram os desabrigados e todos esses somatórios de acontecimentos negativos impactaram socialmente a vida da população, não só da margem ribeirinha do rio mundaú, más de toda a população de União dos Palmares.

De uma maneira ou de outra, todos foram direta ou indiretamente afetados, todos nos vimos nas mesmas situações, buscando soluções nos primeiros dias após a enchente, pois afinal a vida seguia e foi preciso enfrentar os problemas de frente para ter resoluções ou paliativos imediatos, no intuito de trazer alento a uma gente que já havia sofrido muito com aquela tragédia que se abateu sobre a nossa querida União dos Palmares.

Somado a tudo isto, ainda faltou água potável. E o que gerou outro grande problema e por alguns meses, a energia elétrica, teve que ser emprestada, até se restabelecer a instalação dos postes pelos quais é transmitida a fiação da rede elétrica que alimenta a subestação de energia de União dos Palmares e distribui para as residências e logradouros em gerais da cidade.

\section{CONSIDERAÇÕES FINAIS}

Este artigo procurou abordar a enchente ocorrida em União dos Palmares/AL no ano de 2010, trazendo à tona as conseqüências desse desastre climático que ficaram na parte ambiental e social. Impactos estes que ainda não foram totalmente sanados e esquecidos, só acontecerão ao longo dos anos e até de décadas, pois estes impactos foram de grandes dimensões e dessa forma levará um tempo para a resolução doa mesmos. Abordamos as possíveis causas que levaram a uma dimensão maior dessa catástrofe, a exemplo e procuramos sugerir soluções simples às quais em outras enchentes que possivelmente virão ser postas em prática, estas sugestões de soluções, poderão ajudar na minimização de perdas materiais e de vidas humanas e animais.

Hoje as margens ribeirinhas do Rio Mundaú encontram-se desabitadas e sendo assim é necessário e oportuno que comece a plantar a mata ciliar, desassorear o rio, aprofundar seu leito revitalizando assim este rio na parte urbana e rural de nossa cidade. Mas é bem verdade que será preciso um conjunto de ações em toda sua extensão para que dessa forma surta efeito na época chuvosa, pois enchentes sempre terão, agora os impactos de toda natureza podem ser muito, mas infinitamente menores. Por tudo isto, orientamos que sigamos a natureza, as normas ambientais e técnicas para juntos devolvermos a vida ao Rio Mundaú e nos precavermos das futuras enchentes que um dia virão.

Em nossas visitas as margens do rio Mundaú, olhando todo aquele cenário que hoje se mostra calmo e solitário, muito diferente daqueles dias de tormentas ocorridos em junho de 2010, chegamos à conclusão que, a vida naquele lugar, naquela paisagem, as relações sociais e fluxo de pessoas nunca mais será a mesma. Aquela tragédia mudou para sempre a vida naquele local e foi de tamanha dimensão, que poderá surgir uma mata ciliar, uma nova rodovia, como já surgiu, um parque botânico, pessoas a trefegar, mas nunca afixação pessoas a habitar aquela margem ribeirinha, isto porque as consequências da inundação foram enormes e deixaram marcas destrutivas que impossibilitam o habitar de novo daqueles que alí pretendem voltar a morar.

As margens do rio mundaú, outrora, um bairro com vidas humanas e relações sociais, hoje um local deserto, melancólico e solitário, a vida estará presente apenas de passagem, nunca mais em forma de residências, convívio social e troca de experiências humanas, essa é a conclusão obvia que constatamos e que registramos no presente artigo sobre evento tão danoso que se abateu sobre União dos Palmares.

\section{REFERÊNCIAS}

ARAÚJO, L. M. (org.) Geografia: espaço, tempo e planejamento. - Maceió: EDUFAL, 2004. 
CARloS, A. F. A. A cidade. $8^{a}$ ed. São Paulo: Contexto, 2008.

DOLLFUS, O. O espaço geográfico. Tradução de Heloysa de Lima Dantas. Ed. Bertrand Brasil. $5^{\circ}$ edição; Rio de Janeiro, 1991.

MOREIRA, S.M - Depoimento sobre a enchente em União dos Palmares em 2010 (SIC), morador de área ribeirinha.

PIAU, P. Relator do Novo Código Florestal, PL $\mathrm{n}^{\circ}$ 1876/99 (deputado federal por Minas Gerais)

SALLES, I. H. F. Conceitos de geografia física: $2^{\circ}$ grau e curso preparatório para vestibulares. - São Paulo: Ícone, 1997.

SANTOS, M. Por uma Geografia Nova: Da Crítica da Geografia a uma Geografia Crítica. - 6. ed. São Paulo: Editora da Universidade de São Paulo, 2004.

VALENTE, O. F. artigo Enchente e Urbanização.

São Paulo, 2010. p. 2. 